\title{
Aridland Springs in North America: Ecology and Conservation
}

\author{
Lawrence E. Stevens and Vicky J. Meretsky, editors. 2008. The University of Arizona Press and the Arizona-Sonora \\ Desert Museum, Tucson.Pp. 406, 4 black-and-white photos, 28 illustrations, 38 tables, 8 maps, bibliography. \\ $\$ 75.00$ (cloth). ISBN 978-0-8165-2645-1.
}

\section{Reviewed by Kate Smith}

Reviewer Address: 421 W North St, Fayetteville, AR 72701

teosholo@gmail.com

Received: November $1^{\text {st }} 2011$

Volume 3:14-15

Published: March $9^{\text {th }} 2012$

In the words of reviewer R. L. Wallace (2009:1535), "this volume is a must read for those interested in oases or the future of water in the western states." This book represents the combined efforts of twenty-seven authors to holistically address the ecology and conservation of springs in the arid areas of North America. The authors largely meet these goals, gathering their individual expertise and styles to shed light on a greater whole. It is always exciting to see a book truly embrace the interdisciplinary nature of ecology and of conservation efforts, and this book manages to do that. Topics covered in the seventeen chapters include, but are not limited to, the history of springs, groundwater hydrology, ecological case studies, conservation efforts, endemic species, anthropogenic alterations, conservation laws, ethnoecology, and paleobiology.

The book opens with a foreward by Gary Paul Nabhan, who reminds us of the urgency of protecting water resources and of how unique aridland springs are. The authors of Aridland Springs have provided an immensely readable summary of current understanding of the springs and the threats to them. The first four chapters serve to introduce the readers to aridland springs: their historical significance, locations, origins, and classification systems. Chapters six through eight provide case studies of specific springs ecosystems, while nine through eleven address biogeographic distributions of vegetation and terrestrial productivity. Chapter fourteen predicts how the flora and distribution of Great Basin springs will likely change with groundwater withdrawal, while chapter fifteen examines the recovery of a hanging garden spring after accidental human torching of the vegetation. Sixteen examines the legal issues of spring conservation and seventeen summarizes the current research gaps and the conservation challenges still remaining.

Now, if the reader has been paying attention, he or she will realize that chapters five, twelve, and thirteen were omitted from that brief summary. That is because although the previously mentioned chapters provide excellent information, data, research, arguments, and more, these three specific chapters specifically focus on ethnoecology. Chapter five, written by Vance Haynes, examines the paleoecology and paleontology of springs, with examples of human use of the aridland springs primarily as hunting grounds and many springs likely remaining relatively untouched by humans until recent history. The springs that do show a long archaeological and ethnographic history of human use are addressed in chapters twelve and thirteen, which both examine the Quitovac and Quitobaquito springs for Holocene interactions of humans at the springs. Both authors, Nabhan and Amadeo Rea, conclude that the indigenous spring management was likely more effective at preserving spring function and biodiversity than current management practices by the federal government. These conclusions are indirectly supported by the earlier history of conservation issues of the springs provided in chapter two, which stress the difficulties in finding a functioning conservation strategy for the springs that balances the need for disturbance with obliteration of these delicate systems in the xeriscape.

For those interested in applied ethnobiology and ethnoecology, books like Aridland Springs in North America are gems. The book has combined the works of experts in their fields to provide a truly interdisciplinary review of the current understanding and value of the springs. It documents conservation efforts that have been tried, ecological case studies of three types of 
springs, the legalese surrounding the springs, their cultural and archaeological significance, and their responses to human alterations. The authors have reviewed the causes and symptoms of the ongoing decline and destruction of the springs, their biotic and functional importance, and how different groups of people have used the springs in ways that help or hurt them. In sum, this book provides an excellent interdisciplinary window into the aridland springs of North America and is worthy of inclusion in any ethnoecologists' library.

\section{References Cited}

Stevens, L.E. and V.J. Meretsky, eds. 2008. Aridland Springs in North America: Ecology and Conservation. The University of Arizona Press and the Arizona-Sonora Desert Museum, Tucson, AZ.

Wallace, R.L. 2009. Review: Aridland Springs in North America: Ecology and Conservation. Choice 46:1535. 